http://jmscr.igmpublication.org/home/ ISSN (e)-2347-176x ISSN (p) 2455-0450 crossref DOI: https://dx.doi.org/10.18535/jmscr/v8i1.32

\author{
Journal Of Medical Science And Clinical Research \\ IGM Publication \\ An official Publication of IGM Publication
}

$\underline{\text { Research Article }}$

\title{
Prescribing patterns of antihypertensive drugs: An observational hospital based study in outpatient department of a medical college in north India
} Authors

\section{Ajay Kumar ${ }^{1}$, Apoorva Malhotra ${ }^{2 *}$, Pavan Malhotra ${ }^{3}$, Srishti Mantoo ${ }^{4}$}

${ }^{1}$ Assoc. Prof. Department of Pharmacology, Acharya Shri Chander College of Medical Sciences \& Hospital, Sidhra, Jammu, J\&K

${ }^{2}$ Demonstrator Department of Pharmacology, Acharya Shri Chander College of Medical Sciences \& Hospital, Sidhra, Jammu, J\&K

${ }^{3}$ Professor Department of Pharmacology, Acharya Shri Chander College of Medical Sciences \& Hospital, Sidhra, Jammu, J\&K

${ }^{4}$ Asstt. Prof. Department of Pharmacology, Acharya Shri Chander College of Medical Sciences \& Hospital,

Sidhra, Jammu, J\&K

*Corresponding Author

Dr Apoorva Malhotra

Demonstrator, Department of Pharmacology, Acharya Shri Chander College of Medical Sciences \&

Hospital, Sidhra, Jammu, J\&K 180017, India

\begin{abstract}
Background: The purpose of the study is to evaluate the prescribing pattern of drugs used in the management of hypertension in a tertiary care teaching hospital

Methods: A prospective study was conducted for the period of 5 months in an out-patient department. Prescription of males and females with diagnosed primary essential hypertension as per (JNC-VIII guidelines and patients receiving or prescribed with antihypertensive drugs were included. The collected was analyzed for the demographic profile of the patients and the prescribing pattern of antihypertensive drugs used in the management of hypertension.

Results: A total of 200 prescriptions were evaluated during study period, $51 \%$ were male and $49 \%$ were females respectively. Mean age of males and females was $52.7 \pm 1.3$ and $48.03 \pm 0.4$ years respectively. Dual therapy (61\%) followed by monotherapy (20.5\%) and multidrug therapy (18.5\%) was prescribed to hypertensive patients. ARB+Diuretics (33.6\%) followed by ARB+beta blocker (17.2\%), ARB+CCB (17.2\%) and ACEI+Diuretic (9.8\%) were used in dual therapy. Angiotensin receptor blockers (44.73\%) are most widely prescribed drugs followed by CCB (21.05\%), ACEIs (14.6\%), Diuretics (10.52\%) and Beta blockers $(10.52 \%)$ in monotherapy. In triple drug therapy most common combination was Diuretic $+A R B+A C E I s$ $(18.91 \%)$ and $A R B+B e t a$ blocker $+C C B(18.91 \%)$. Single drug therapy ARB reduced SBP by $18.5 \%$ and $D B P$ by $12.5 \%$ and in dual therapy combination of $A R B$ and beta blocker reduced SBP by $22.16 \%$ \& $C C B+A C E I$ reduced DBP by $19.31 \%$.

Conclusions: Dual therapy was frequently prescribed regimen followed by multidrug and monotherpy. $A R B+$ Diuretic was most preferred treatment. In monotherapy most preferred drug was ARB followed by $C C B$. The prescribing patterns of anti $H T$ drugs moderately followed standard treatment as per international guidelines for hypertension

Keywords: Prescription, Antihypertensives, Blood pressure, JNC-VII, Prescription pattern.
\end{abstract}




\section{Introduction}

An imbalance in hemodynamic function that causes a persistent and abnormal elevation of systemic blood pressure either systolic or diastolic or both i.e. > 140mmHg systolic and $>90 \mathrm{mmHg}$ diastolic respectively is labeled as hypertension. The global burden of hypertension (HT) is alarming. The prevalence of HT increases with advancing age. ${ }^{[1]}$ HT affects more men than women until 55 years of age, but thereafter, women supersedes men. ${ }^{[2]}$ Hypertension is considered to be a silent killer. It is a global public health issue and contributes to burden of heart disease, stroke, kidney failure and premature mortality \& disability. It affects populations both in low and middle income countries having fragile health systems which is out of proportion. ${ }^{[3]}$ Hypertension affects approximately 97.2 crore people. About 33.3 crore in economically developed countries and 63.9 crore in economically developing countries in 2000 and is expected to increase up to 15600 crores in $2025 .^{[4]}$ In India hypertension alone accounts for $57 \%$ of deaths due to stroke and $24 \%$ of deaths due to coronary artery disease. ${ }^{[5]}$ Cardiovascular disease accounts for approximately 17 crore deaths a year, nearly one third of the total. ${ }^{[6]}$ Of these, complications of hypertension account for 940 lac deaths worldwide every year. ${ }^{[7]}$ Hypertension is responsible for at least $45 \%$ of deaths due to heart disease (total ischemic heart disease mortality), and $51 \%$ of deaths due to stroke (total stroke mortality). Therefore it is important to control increased blood pressure. Rational prescription patterns are defined as patients receiving medications according to their medical condition, in doses that meet their requirements, for an adequate period of time, and at affordable cost to them and the society. Appropriate prescribing has a positive implication on medication adherence and disease improvement. ${ }^{[8]}$

In regular practice with hypertension, it is observed that there is deviation from evidence based guidelines in treating hypertensive patients. There is growing evidence of irrational prescribing of antihypertensive agents, which also leads to increased burden on health care system, so it is necessary to analyze prescribing pattern and adherence to authorized guidelines. A number of national and international guidelines for the treatment of hypertension have been published. The JNC-8 guidelines recommend diuretics as the first line treatment in hypertension. The European guidelines, on the other hand, suggest that unless a special indication exists, any of the five anti hypertensive classes can be used as first line treatment. A combination treatment has been recommended as first line intervention, particularly in patient with severe hypertension. Blood pressure lowering drugs include several classes of drugs, angiotensin converting enzyme inhibitors (ACEIs), Angiotensin II receptor antagonists (ARBs)), Beta-blockers (BBs), diuretics, calcium channel blockers (CCBs), $\alpha-$ blockers, peripheral vasodilators. Various lifestyle modifications include losing weight, quitting smoking, eating a healthy diet, reducing sodium intake, exercising regularly, and limiting alcohol consumption or both. ${ }^{[10]}$ The Joint National Committee (JNC-8) is considered the "gold standard" consensus guidelines for the management of hypertension. About goals of older individuals, a 2014 report from panel members of the Eighth Joint National Committee (JNC8) suggested that in patients aged $\geq 60$ years, blood pressure should be targeted to $<150 / 90 \mathrm{~mm}$ $\mathrm{Hg} .{ }^{[11]}$ There is paucity of literature about prescribing patterns and adherence to JNC-8 guidelines while prescribing anti hypertensives among hypertensives in this part of country. The pourpose of this study was to assess sociodemographic profile of hypertensives and use of anti hypertensive drugs for management of hypertension in order to establish current trend of pattern of prescribing of anti-HT drug and adherence with international guidelines.

\section{Methods}

An observational hospital based prescription study was carried out from August 2019 to December 
2019 after approval from Institutional Ethics Committee in teaching tertiary care hospital of North India. A total of 200 prescriptions of diagnosed HT, were collected from patients visiting the outpatient department of medicine. Patients of either sex with primary essential hypertension diagnosed as per JNC-8 guidelines and more than 25 years of age were included in the study. Time since diagnosis was more than six months. Each prescription included the drug, quantity, duration, and date of prescribing. Exclusion criteria included patients below 18 years, pregnant females, those unwilling to participate those attending emergency department, seriously ill, secondary hypertension and hypertension CVA, severe renal and hepatic disease. All the patients were approached at pharmacy shop and outside OPD without knowledge of prescriber to avoid any bias. Verbal consent was taken from subjects and accompanying person. Prescriptions were assessed for number of drugs prescribed, dosage, route, duration of treatment, class of anti-HT and utilization pattern. Quality was judged in terms of handwriting- whether legible or illegible, use of abbreviations and frequency of dosage. Data was recorded from patients receiving antihypertensives as those receiving monotherapy, dual therapy and multidrug combination therapy. Each antihypertensive medication was categorized into one of the following classes: thiazide-type diuretics, angiotensin converting enzyme inhibitors (ACEIs) or angiotensin receptor blockers (ARBs), calcium channel blockers (CCBs), $\beta$-blockers and other antihypertensive agents. All the patients were followed up once during study period. Microsoft excel software was used to calculate percentage, mean and standard deviation.

\section{Results}

A total of 200 prescriptions were evaluated during the observation period to assess the utilization pattern. Table 1 summarizes the demographic characteristics of these patients. 102 prescription
(51\%) and 98 prescriptions (49\%) belonged to males and females respectively. Mean age of male and female patients were found to be $52.7 \pm 13$ and $48.03 \pm 0.4$ respectively. Most of the prescriptions $(34 \%)$ were from age group of 41-50 years. Education status of $18.5 \%, 9.5 \%$ and $17 \%$ patients was secondary, graduate and higher (including professional) level respectively. $110(55 \%)$ of the patients had a positive family history of hypertension and $80(40 \%)$ had a BMI $<25 \mathrm{Kg} / \mathrm{m} 2$. $111(55.5 \%)$ of patients had single comorbidity and $35(17.5 \%)$ multiple comorbidities, whereas 54 (27\%) had no comorbidities. Prescription handwriting was readable in $90 \%$ of prescription orders as against non readable prescriptions. The breakup of hypertensive patients according to JNC-8 guidelines was 59 (29.5\% Pre HT), 82 (41\% Stage I) and 40 (20\% Stage II) cases. The mean SBP was $157.18 \pm 6.97 \mathrm{mmHg}$ and $154.18 \pm 6.46 \mathrm{mmHg}$ in males and females respectively. The mean DBP was $96.16 \pm 1.17$ $\mathrm{mmHg}$ and $94.06 \pm 1.01 \mathrm{mmHg}$ in males and females respectively. Patterns of use of various classes of anti hypertensive drugs as monotheray, dual therapy and multidrug therapy and utilization pattern is presented in table 2 . This study revealed that physicians prescribed dual therapy $(61 \%)$ to control BP followed by monotherapy $(20.5 \%)$ and multidrug therapy $(18.5 \%)$. In dual therapy most commonly prescribed drugs were ARB+Diuretics (33.6\%) followed by ARB+beta blocker (17.2\%), $\mathrm{ARB}+\mathrm{CCB}(17.2 \%)$ and ACEI+Diuretic (9.8\%) and others. Angiotensin receptor blockers $(44.73 \%)$ are most widely prescribed drugs followed by CCB (21.05\%), ACEIs (14.6\%), Diuretics $(10.52 \%)$ and Beta blockers $(10.52 \%)$ in monotherapy. In triple drug therapy most common combination was Diuretic+ARB+ACEIs (18.91\%) and ARB+Beta blocker+CCB (18.91). Other prescription orders contained Diuretic+ $\mathrm{ARB}+\mathrm{CCB}(16.21 \%)$ and Diuretic+ARB+BB (10.8\%). In quadruple therapy most common combination was ACEIs+Diuretic+Beta blocker+CCB (16.21\%). Table 3 shows the most effective drug preferred to reduce SBP \& DBP in 
monotherapy and dual therapy. In single drug therapy ARB reduced SBP by $18.5 \%$ and DBP by $12.5 \%$ and in dual therapy combination of ARB and beta blocker reduced SBP by $22.16 \%$ \& CCB+ACEI reduced DBP by $19.31 \%$. While taking history from patients and their attendants it was observed that drug compliance was good in both males and females. The prescription pattern showed a good adherence with the prescribed treatment in accordance with both Indian and international guidelines.

Table 1 Demographic details of patients

\begin{tabular}{|c|c|}
\hline Demographics & No. $(\%)$ \\
\hline \multicolumn{2}{|l|}{ 1. Age (Years) } \\
\hline $25-40$ & $36(18)$ \\
\hline $41-50$ & $68(34)$ \\
\hline $51-60$ & $56(28)$ \\
\hline $61-70$ & $32(16)$ \\
\hline$>70$ & $8(4)$ \\
\hline \multicolumn{2}{|l|}{ 2. Gender } \\
\hline Male & $102(51)$ \\
\hline Female & $98(49)$ \\
\hline \multicolumn{2}{|l|}{ 3. Eating habits } \\
\hline Vegetarian & $112(56)$ \\
\hline Non vegetarian & $88(44)$ \\
\hline \multicolumn{2}{|l|}{ 4. Prescription hand writing } \\
\hline Readable & $180(90 \%)$ \\
\hline Nonreadable & $20(10 \%)$ \\
\hline \multicolumn{2}{|l|}{ 5. Educational status } \\
\hline Illitrate & $50(25)$ \\
\hline Upto $8^{\text {th }}$ standarad & $60(30)$ \\
\hline Upto $12^{\text {th }}$ standarad & $37(18.5)$ \\
\hline Graduate & $19(9.5)$ \\
\hline Higher+Prof. Education & $34(17)$ \\
\hline \multicolumn{2}{|l|}{ 6. Habits } \\
\hline Non alc \& non smokers & $50(25)$ \\
\hline Smokers \& alcoholic & $86(43)$ \\
\hline Tobacco chewers & $64(32)$ \\
\hline \multicolumn{2}{|l|}{ 7. Comorbidities } \\
\hline Single & $111(55.5)$ \\
\hline Multiple & $35(17.5)$ \\
\hline No comorbidities & $54(27)$ \\
\hline \multicolumn{2}{|l|}{ 8. Family history } \\
\hline Absent & $90(45)$ \\
\hline Present & $110(55)$ \\
\hline \multicolumn{2}{|l|}{ 9. Body mass index $(\mathrm{kg} / \mathrm{m} 2)$} \\
\hline$<25$ & $80(40)$ \\
\hline $25-29.9$ & $65(32.5)$ \\
\hline $30-40$ & $50(25)$ \\
\hline$>40$ & $5(2.5)$ \\
\hline \multicolumn{2}{|c|}{ 10. Stages of hypertension (JNC-8) } \\
\hline Normal & $19(9.5)$ \\
\hline Prehypertension & $59(29.5)$ \\
\hline Stage-1 & $82(41)$ \\
\hline Stage-2 & $40(20)$ \\
\hline
\end{tabular}


Table 2: Anti hypertensive medications used patients in monotherapy, dual therapy and multiple drug combinations

\begin{tabular}{|lc|}
\hline Pharmacotherapy & No. $(\%)$ \\
\hline Monotherapy & $\mathbf{4 1}(\mathbf{2 0 . 5})$ \\
\hline ARBs & $18(44.73)$ \\
\hline ACEIs & $6(14.6)$ \\
\hline BETA BLOCKERS & $4(10.52)$ \\
\hline ALPHA BLOCKERS & $1(2.63)$ \\
\hline CCB (DHPs) & $8(21.05)$ \\
\hline Diuretics & $4(10.52)$ \\
\hline Dual therapy & $122(61)$ \\
\hline ARB+Beta Blocker & $21(17.2)$ \\
\hline ARB+Thiazide diuretic & $41(33.6)$ \\
\hline Beta Blocker+Thiazide diuretic & $9(7.3)$ \\
\hline CCB Dihydropyridine+ACEI & $6(4.9)$ \\
\hline Beta blocker+CCB Dihydropyridine & $6(4.9)$ \\
\hline ARB+CCB Dihydropyridine & $21(17.2)$ \\
\hline ACEI+Thiazide diuretic & $12(9.8)$ \\
\hline ARB+Alpha blocker & $2(1.6)$ \\
\hline ARB+CCB Benzothiazepines & $2(1.6)$ \\
\hline ACEI+CCB Benzothiazepines & $2(1.6)$ \\
\hline Multiple drug therapy & $37(18.5)$ \\
\hline Triple Therapy & \\
\hline Diuretic+ARB+CCB & $6(16.21)$ \\
\hline Diuretic+ARB+ACEI & $7(18.91)$ \\
\hline Diuretic+ARB+Beta Blocker & $4(10.8)$ \\
\hline ARB+Beta blocker+CCB & $7(18.91)$ \\
\hline Diuretic+ARB+Alpha blocker & $2(5.40)$ \\
\hline Quadruple Therapy & $6(16.21)$ \\
\hline ACEI+Diuretic+Beta blocker+CCB & $3(8.10)$ \\
\hline ARB+Beta blocker+Diuretic+CCB & $2(5.4)$ \\
\hline ARB+Diuretic+Alpha blocker+CCB & \\
\hline b & \\
\hline
\end{tabular}

$\mathrm{ARB}=$ angiotensin receptor blocker, $\mathrm{ACEIs}=$ angiotensin converting enzyme inhibitors,

$\mathrm{CCB}(\mathrm{DHPs})=$ calcium channel blockers (dihydropyridines)

Tab 3: Percentage reduction in SBP and DBP in monotherapy, dual therapy and multidrug therapy

\begin{tabular}{|c|c|c|c|c|c|c|}
\hline \multicolumn{4}{|l|}{ Monotherapy } & \multicolumn{3}{|c|}{ Monotherapy } \\
\hline $\begin{array}{l}\text { Drug } \\
\text { Class }\end{array}$ & BSBP & SBP & Reduction of SBP (\%) & BDBP & Red & $\begin{array}{l}\text { tion of } \\
3 P(\%)\end{array}$ \\
\hline ARB & $157.18 \pm 6.97$ & $128.11 \pm 5.45$ & 18.5 & $96.16 \pm 6.98$ & $84.14 \pm 5.34$ & 12.5 \\
\hline $\mathrm{CCB}$ & $155.52 \pm 9.76$ & $130.11 \pm 6.94$ & 16.35 & $94.34 \pm 5.12$ & $86.11 \pm 5.76$ & 8.73 \\
\hline ACEI & $153.54 \pm 7.45$ & $133.89 \pm 4.78$ & 12.82 & $93.83 \pm 8.23$ & $86.02 \pm 4.98$ & 8.33 \\
\hline Diuretics & $50.23 \pm 6.52$ & $135.33 \pm 5.69$ & 9.92 & $91.1 \pm 7.12$ & $86.41 \pm 6.32$ & 5.15 \\
\hline \multicolumn{4}{|l|}{ Dual therapy } & \multicolumn{3}{|c|}{ Dual therapy } \\
\hline Diuretic+ARB & $159.3 \pm 11.7$ & $132.86 \pm 9.76$ & 16.6 & $98.46 \pm 6.32$ & $83.84 \pm 7.54$ & 14.85 \\
\hline $\mathrm{ARB}+\mathrm{BB}$ & $160.8 \pm 8.4$ & $125.16 \pm 8.53$ & 22.16 & $99.89 \pm 5.6$ & $82.68 \pm 7.21$ & 17.22 \\
\hline BB+Diuretic & $159.8 \pm 13.3$ & $135.17 \pm 6.05$ & 15.41 & $95.87 \pm 8.96$ & $81.15 \pm 6.66$ & 15.35 \\
\hline CCB+ACEI & $160.7 \pm 10.5$ & $126.7 \pm 87$ & 20.01 & $99.53 \pm 8.45$ & $80.18 \pm 7.23$ & 19.31 \\
\hline \multicolumn{4}{|l|}{ Multiple drug therapy } & \multicolumn{3}{|c|}{ Multiple drug therapy } \\
\hline $\mathrm{ARB}+\mathrm{BB}+\mathrm{CCB}$ & $162.7 \pm 11.2$ & $2 \quad 128.37 \pm 6.34$ & 21.1 & $99.9 \pm 8.98$ & $80.12 \pm 3.98$ & 19.8 \\
\hline $\mathrm{ARB}+$ Diuretic+BB+CCB & В $165.3 \pm 8.4$ & $120.12 \pm 8.2$ & 25.15 & $100.23 \pm 6.6$ & $81.44 \pm 4.5$ & 20.54 \\
\hline
\end{tabular}

\section{Discussion}

Hypertension is a chronic disease which requires lifelong management. A prescription-based survey is considered to be one of the most effective methods to assess and evaluate the prescribing attitude of physicians. ${ }^{[12]}$ and dispensing practice 
of pharmacists. It is also important to consider the recommendations of international bodies on hypertension that help to improve prescribing practice of the physicians and ultimately, the clinical standards. A continuous supervision is therefore required through such kinds of systematic audit, that provide feedback from the physician and help to promote rational use of drugs. ${ }^{[13]}$ This study analyzed the prescribing pattern in hypertensive patients attending a tertiary care hospital outpatient department. Selection of antihypertensive should be based on the benefit an a patient taking into consideration various compelling conditions like diabetes mellitus, untoward effects of drugs and its pharmacoeconomic impact. Reducing mortality and morbidity asscociated with hypertension is the final goal of treatment. ${ }^{[14]}$ In this study it was observed that $102(51 \%)$ of total prescriptions belonged to males and 98 (49\%) of total prescriptions belonged to females. Review of literature reveals that there is no consistence in gender distribution of patients suffering from hypertension. While some studies suggest high percentage of hypertension in males and on the contrary others suggest high percentage in females. ${ }^{[15],[16]-[25]}$ "Tiwary et $\mathrm{al}^{[13]}$ found that hypertension is more common in age group 50-59 (33\%) followed by 60-69 and 40-49 (26.7\%)". Our study also revealed that it is most common in age group 41-50 years (34\%) followed by 51-60 $(28 \%)$ and 61-70 (16\%). Present study showed $55.5 \%$ patients had associated co morbidity like diabetes mellitus, and cardiovascular diseases, while $17.5 \%$ had associated co morbidity. Some studies have reported $36.6 \%{ }^{(26)}$ and $47.7 \%^{(20)}$ patients respectively were suffering from co morbid conditions. It was observed that $61 \%$ of patients were prescribed combination therapy (i.e. more than one anti HT in the prescription) which is lower than the recommendations ${ }^{(27)}$ and observations of several other studies which demonstrated that combination was necessary in at least $70 \%$ of study population to attain optimal blood pressure control ${ }^{(28,29)}$. Our study shows diuretics alone or in combination are most frequently prescribed classes of drugs. JNC 8 recommends the use of ACEIs, ARBs, diuretics and CCB alone or in combination for management of early stage hypertension, thus suggesting trend of prescriptions is in conformity with JNC 8 guidelines. ${ }^{[11]}$ In our study most widely prescribed drugs in monotherapy were ARBs followed by CCBs, ACEIs beta blockers and diuretics. In some cases alpha blockers were also used. This prescription trend is similar to JNC guidelines. Similar prescription trend was also seen in previous studies. ${ }^{[30]}$ In this study the most common drug used in combination therapy is $\mathrm{ARB}+$ Thiazide diuretic $(33.6 \%)$ followed by $\mathrm{ARB}+$ Beta blocker (17.2\%), ARB+CCB (17.2\%) and Beta blocker+Thiazide diuretic (7.3\%). Among multidrug therapy most common combination prescribed in our study was Diuretic+ARB+ ACEIs(18.91\%) and ARB+Beta Blocker+CCB (18.91\%) followed by $\mathrm{ARB}+$ Diuretic+CCB (16.21\%) and in four drug therapy ACEI+Diuretic+BB+CCB (16.21\%). Previous studies have also shown that diuretics alone or in combination with ARBs, CCB, ACEI can be used with successful outcomes. [24],[25],[30] This trend is akin to JNC guidelines and results shown by Fischer et al. ${ }^{[31]}$ "Tiwari et $\mathrm{al}^{[13]}$ recorded $46.2 \%$ prescriptions had beta blockers in monotherapy which is very high in comparison to present study which might be due to changing drug prescription trends and fear of adverse effects of beta blockers in elderly population". ACE inhibitors (3.9\%) and ARBs prescription rates in their study was too low in comparison to our study. This might be because of recently gained popularity of ARBs and ACEIs. In a study by by "Dhanraj et al ${ }^{[32]}$ prescription rates of ACEIs (59\%) followed by ARBs (52\%), CCBs (29\%), and are unlike our study as far as ACEIS are concerned, which may be because study population in this study was HT with diabetes mellitus". In comparison of reduction of SBP in monotherapy vs dual therapy $\mathrm{ARB}+\mathrm{BB}$ reduce more $\mathrm{BP}$ than $\mathrm{ARB}$ alone. Regarding DBP high 
percentage of reduction was observed with ARB while as $\mathrm{CCB}+\mathrm{ACEI}$ combination caused more reduction in DBP. This study has provided an insight into prescription patterns of antihypertensive medications with respect to the level of BP control and it may help prescribers to pay more attention for specific factors that affect outcome of BP. This study had some limitations also. Duration of study was only for a period of 5 months. Data was collected from only one institution in a homogenous population and not general population. Even it was beyond the scope the current study to asses' rationality in terms of comorbid conditions and antiHT prescription.

\section{Conclusions}

In general dual therapy was frequently prescribed regimen followed by multidrug and monotherpy. $\mathrm{ARB}+$ Diuretic was most preferred treatment. In monotherapy most preferred drug was ARB followed by CCB. The prescribing patterns of anti HT drugs moderately followed standard treatment as per international guidelines for hypertension. A regular monitoring of the prescription pattern is essential to keep a tab on the rational drug prescriptions for a better therapeutic outcome. Clinicians should be vigilant to consider regimen changes if contemporary regimens do not control blood pressure up to satisfactory levels, because therapeutic modifications could bring an improvement in blood pressure.

\section{Acknowledgements}

We acknowledge patients and attendents who participated in present study so as to use the data and interpret it.

Funding: None

Conflict of interest: None declared

Ethical approval: Approved by IEC

\section{References}

1. Franklin SS, Gustin W, 4th, Wong ND, Larson MG, Weber MA, Kannel WB, et al. Hemodynamic patterns of age-related changes in blood pressure. The Framingham heart study. Circulation. 1997;96:308-15.

2. Harrison-Bernard LM, Raij L. Postmenopausal hypertension. Curr Hypertens Rep. 2000;2:202-7.

3. A global brief on hypertension: Silent killer, global public health crisis. WHO/DCO/WHD/2013.2.

http://www.who.int/cardiovascular_diseas es/publications/global_brief_hypertension/ en/. Accessed 11th Dec 2019.

4. Kearney PM, Whelton M, Reynolds K, Muntner P, Whelton PK, He J. Global burden of hypertension: analysis of worldwide data. Lancet. 2005;365(9455): 217-23.

5. Gupta R. Trends in hypertension epidemiology in India.J Hum Hypertens. 2004 ;Feb;18(2):73-8.

6. Causes of Death 2008 [online database]. Geneva, World Health Organization. http ://www.who.int/healthinfo/global_burden_ disease/cod_2008_sources_methods.pdf.A ccessed 14th Dec 2019.

7. Lim SS, Vos T, Flaxman AD, Danaei G, Shibuya K, Adair-Rohani $\mathrm{H}$, et al. A comparative risk assessment of burden of disease and injury attributable to 67 risk factors and risk factor clusters in 21 regions, 1990-2010: a systematic analysis for the Global Burden of Disease Study 2010. Lancet. 2012;380 (9859):2224-60.

8. Shrank WH, hoang T, Ettner SL, etal. The implications of choice: prescribing generic or preffered pharmaceuticals improves medication adherence for chronic conditions. Arch intern Med. 2006;166(3):332-337.

9. Sepehri G, Talebizadeh N, Mirzazadeh A,Mohsenbeigi M. The patterns of antihypertensive drug prescription by cardiologists in Kerman province of Iran, 2006. Pharmacoepidemiol Drug Saf. 2008;17:180-5. 
10. Chiang CW, Chen CY, Chiu HF, Wu HL, Yang CY. Trends in the use of antihypertensive drugs by outpatients with diabetes in Taiwan, 1997-2003. Pharmacoepidemiol Drug Saf. 2007; 16:412-21.

11. James PA, Oparil S, Carter BL, Cushman WC, Dennison-Himmelfarb C, Handler J, et al. evidence-based guideline for the management of high blood pressure in adults: report from the panel members appointed to the Eighth Joint National Committee (JNC 8). JAMA. 2014;311:507-20.

12. Yuen YH, Chang S, Chong CK, Lee SC, Critchlev JA, Chan JC. Drug utilization in a hospital general medical outpatient clinic with particular reference to antihypertensive and antidiabetic drugs. J Clin Pharm Ther 1998; 23:287-94.

13. Tiwari H, Kumar A, Kulkarni SK. Prescription monitoring of antihypertensive drug utilization at the Punjab University Health Centre in India. Singapore Med J. 2004;45(3):117-20.

14. Dipiro JT, Talbert RL, Yee GC, Wells BG, Posey LM. Pharmacotherapy A Pathophysiologic Approach. Seventh edition, 2008, McGraw-Hill Medical, New York, United States of America. 2008.

15. Tasneem S, Vamsi Krishna E. Survey of prescription pattern of anti-hypertensive drugs in hypertensives and hypertension associated diabetics. Int J Pharma Bio Sci. 2010;1(4):23-6.

16. Preethi GP, Jnaneshwara S, Narendranath S. Prescribing patterns of antihypertensive drugs in a South Indian tertiary International Journal of Basic \& Clinical Pharmacology | March-April 2014 | Vol 3 | Issue 2 Page 307 care hospital. Drug Invent Today. 2011;3(4):38-40.

17. Jackson JH, Sobolski J, Krienke R, Wong KS, Frech- Tamas F, Nightengale B. Blood pressure control and pharmacotherapy patterns in the United States before and after the release of the Joint National Committee on the Prevention, Detection, Evaluation, and Treatment of High Blood Pressure (JNC 7)guidelines. J Am Board Fam Med. 2008;21(6):512-21.

18. Jhaj R, Goel NK, Gautam CS, Hota D, Sangeeta B, et al. Prescribing patterns and cost of antihypertensive drugs in an internal medicine clinic. Ind. Heart J. 2001;53:323-7.

19. Malhotra S, Karan R, Pandhi P, Jain S. Pattern of use and pharmacoeconomic impact of antihypertensive drugs in a North Indian referral hospital. Eur J Clin Pharmacol. 2001;57:535-40.

20. Kothari N, Ganguly B. Adherence to JNCVII and WHO-ISH guidelines of antihypertensive medications prescribed to hypertensive patients with co-morbid conditions. Indian J Physiol Pharmacol. 2015;59(1):48-56.

21. Murti K, Khan MA, Dey A, Sethi MK, Das P, Pandey K. Prescription Pattern of Anti-Hypertensive Drugs in Adherence to JNC- 7 Guidelines. American Journal of Pharmacology and Toxicology. 2015;10(1):27-31.

22. Pittrow D, Kirch W, Bramlage P, Lehnert $\mathrm{H}$, Höfler $\mathrm{M}$, et al.. Patterns of antihypertensive drug utilization in primary care. Eur J Clin Pharmacol. 2004;60:135-42.

23. Lee PK, Li RK, Chan JC, Chang S, Lee SC, Tomlinson B, Critchley JA. A prescription survey in a hospital hypertension outpatient clinic. Br J Clin Pharmacol. 1997;44(6):577-82.

24. Cidda M, Mateli UV, Batchu MK, Maratha S. Study of prescribing patterns of anti hypertensives in south Indian population. Int $\mathbf{J}$ Basic Clin Pharmacol 2014;3:303-7 
25. Romday R, Gupta AK, Bhambani P. Assessment of antihypertensive drug prescription patterns and adherence to joint national committee- 8 hypertension treatment guidelines among hypertensive patients attending a tertiary care teaching hospital. Int J Res Med Sci 2016;4:512533.

26. Amira CO, Okubadejo NU. Antihypertensive pharmacotherapy in a developing economy: pattern, acquisition costs and conformity to international guidelines in a tertiary-care setting. Journal of Human Hypertension. 2006;20:894-7.

27. World Health Organization-International Society of Hypertension Guidelines for the Management of Hypertension. Guidelines Subcommittee. J Hypertens. 1999; 17:15183.

28. Chobanian AV, Bakris GL, Black HR, Cushman WC, Green LA, Izzo JL, Jr., et al. The Seventh Report of the Joint National Committee on Prevention, Detection, Evaluation, and Treatment of High Blood Pressure: the JNC 7 report. JAMA. 2003; 289:2560-72.

29. Chalmers J. The ABCD of antihypertensive therapy. J Hypertens. 2002; 20:615-6.

30. Jun M, Lee KV, Randall SS. Changes in antihypertensive prescribing during US outpatient visits for uncomplicated hypertension between 1993 and 2004. Hypertension. 2006;48:846-52.

31. Fischer MA, Avorn J. Economic implications of evidence based prescribing for hypertension: can better care cost less? JAMA. 2004;291(15):1850-6.
32. Dhanaraj E, Raval A, Yadav R, Bhansali A, Tiwari P. Prescription pattern of antihypertensive agents in T2DM patients visiting tertiary care centre in North India. Int J Hypertens. 2012;2012:520915. 